\title{
Stage IVA Lip and Oral Cavity Squamous Cell Carcinoma AJCC v6 and v7
}

National Cancer Institute

\section{Source}

National Cancer Institute. Stage IVA Lip and Oral Cavity Squamous Cell Carcinoma AJCC

v6 and v7. NCI Thesaurus. Code C115061.

Stage IVA includes: (T4a, N0, M0); (T4a, N1, M0); (T1, N2, M0); (T2, N2, M0); (T3, N2, M0); (T4a, N2, M0). T4a: Lip and oral cavity cancer with moderately advanced local disease. Lip: T umor invades through cortical bone, inferior alveolar nerve, floor of mouth, or skin of face, i.e., chin or nose. Oral cavity: T umor invades adjacent structures only (e.g., through cortical bone [mandible or maxilla] into deep [extrinsic] muscle of tongue [genioglossus, hyoglossus, palatoglossus, and styloglossus], maxillary sinus, skin of face). T1: Tumor $2 \mathrm{~cm}$ or less in greatest dimension. T2: Tumor more than $2 \mathrm{~cm}$ but not more than $4 \mathrm{~cm}$ in greatest dimension. T3: Tumor more than $4 \mathrm{~cm}$ in greatest dimension. N0: No regional lymph node metastasis. N1: Metastasis in a single ipsilateral lymph node, $3 \mathrm{~cm}$ or less in greatest dimension. N2: Metastasis in a single ipsilateral lymph node, more than $3 \mathrm{~cm}$ but not more than $6 \mathrm{~cm}$ in greatest dimension; or in multiple ipsilateral lymph nodes, none more than $6 \mathrm{~cm}$ in greatest dimension; or in bilateral or contralateral lymph nodes, none more than $6 \mathrm{~cm}$ in greatest dimension. M0: No distant metastasis. (AJCC 7th ed.) 